UDK: 72.012:004.922

DOI: https://doi.org/10.24867/10FA01Terzin

\title{
PRIMENA DIGITALNIH ALATA U IZRADI KINETIČKIH STRUKTURA KAO ELEMENATA URBANOG MOBILIJARA
}

\section{APPLICATION OF DIGITAL TOOLS IN THE FABRICATION OF KINETIC STRUCTURES AS URBAN FURNITURE ELEMENTS} \section{URBANIZMU}

Oblast - DIGITALNI DIZAJN U ARHITEKTURI I

Kratak sadržaj - Ovaj rad baziran je na istraživanju kinetičkih struktura koje se mogu primenjivati $u$ urbanizmu. Kreiranje kinetičke klupe sa nadstrešnicom pored dizajna strukture iziskuje i detaljan pristup spojnim vezama koje omogućavaju transformaciju. Cilj istraživanja jeste unaprediti postojeće primere kinetičkih struktura tako da zadovoljavaju više korisničkih potreba istovremeno.
\end{abstract}

Milica Terzin, Fakultet tehničkih nauka, Novi Sad parku.

\section{STANJE U OBLASTI}

Ključne reči: kinetička arhitektura, digitalni dizajn, urbanizam

Abstract - This paper is based on the research of kinetic structures which can be utilized in town planning. Apart from designing the structure, designing kinetic bench with canopy requires a detailed approach to connections which enables transformation. The aim of this research is to improve the existing kinetic structures so that they can meet the multiple needs of users simultaneously.

Keywords: kinetic architecture, digital design, urbanism

\section{UVOD}

Prirodno okruženje je jedan od bitnijih faktora koji utiču na arhitektonsko delo. S obzirom da se uslovi iz okruženja konstantno menjaju (ugao sunčevih zraka, pravac duvanja vetra), arhitekte dugi niz pokušavaju pronaći rešenje kako bi se prilagodili tim promenama.

Razvoj ove ideje, kao i raznovrsnost potreba i mogućnosti koje su se ukazale s vremenom, dovele su do pojave više vrsta disciplina koncentrisanih na kreiranje kinetičke arhitekture. Kinetička arhitektura je zgrada i/ili komponenta zgrade sa promenljivom mobilnošću, lokacijom i/ili geometrijom [1].

Govoreći o kinetičkoj arhitekturi, ne misli se samo na elemente koji se pomeraju i time menjaju oblik i fizičke karakteristike objekta, nego o uzrocima pomeranja tih elemenata, odnosno o vezi zgrade sa njenim okruženjem. Prilagodljiva kinetička arhitektura stvara ekološki sistem od komponenata koje se međusobno pomeraju dok daju odgovore na promene iz okruženja [2].

Rešenja iz oblasti kinetičke arhitekture postala su široko primenjiva, što znači da koristeći principe pomerljivog/promenljivog dizajna danas možemo pronaći rešenja

\section{NAPOMENA:}

Ovaj rad proistekao je iz master rada čiji mentor je bio dr Marko Jovanović, docent. najrazličitijih problema počevši od gradova koji se na osnovu prikupljenih podataka s vremenom sve više prilagođavaju svojim korisnicima, preko pokretnih fasada do manjih intervencija kao što su promena oblika klupe $u$

Kinetički elementi urbanog mobilijara mogu na razne načine da utiču na kvalitet života u naselju. Karakteristike analiziranih primera pokazuju raznovrsnost tih mogućnosti, kao i različite pristupe kreiranju kinetičkih struktura.

\subsection{IDO klupa}

IDO klupa predstavlja prvi i najjednostavniji primer kinetičke klupe. Karakteristika IDO sedišta su njeni segmentni delovi u obliku bumeranga, koji korisnicima klupe fiksirane za pod omogućavaju da izaberu na koju stranu će ona biti orijentisana, što se vidi na slici 1. Koncept ovog dizajna leži u rotiranju simetričnih segmenata oko jedne horizonalne ose.

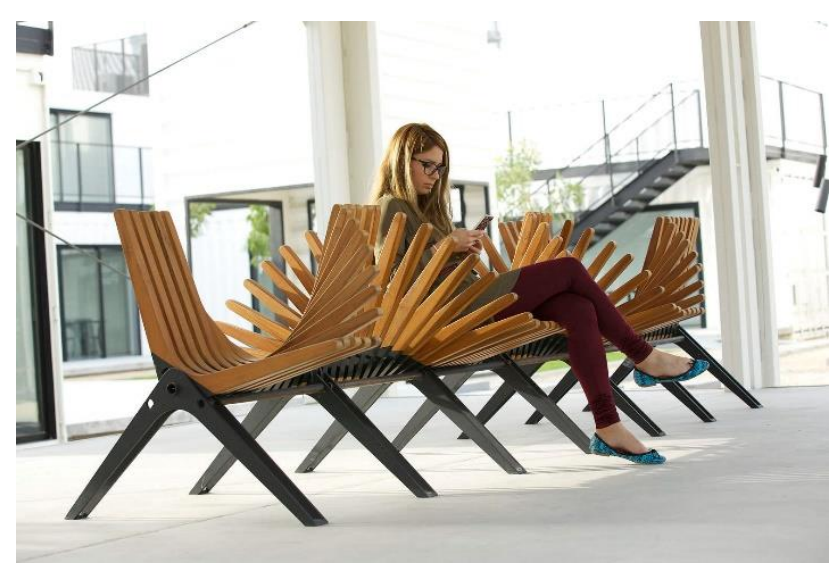

Slika 1. IDO struktura u enterijeru [3]

Pored toga što je estetski efektno, ovo je veoma korisno rešenje za galerije i muzeje, kao i otvorene prostore sa zanimljivim urbanim rešenjima gde korisnici svojim afinitetima mogu prilagoditi deo urbanog mobilijara.

\subsection{Talasasta klupa}

Napredak dizajna po pitanju udobnosti u odnosu na IDO strukturu jeste „Talasasta klupa“ (Wave bench) koja se prilagođava korisnicima tako da je ergonomski efektivnija. Talasasta klupa zapravo postaje klupa tek kada je korisnik 'aktivira'. Segmenti od kojih je načinjena stoje uspravno sve dok korisnik ne izvrši pritisak na nju i tako 
delove klupe prilagodi svom obliku tela, kao što se vidi na slici 2.

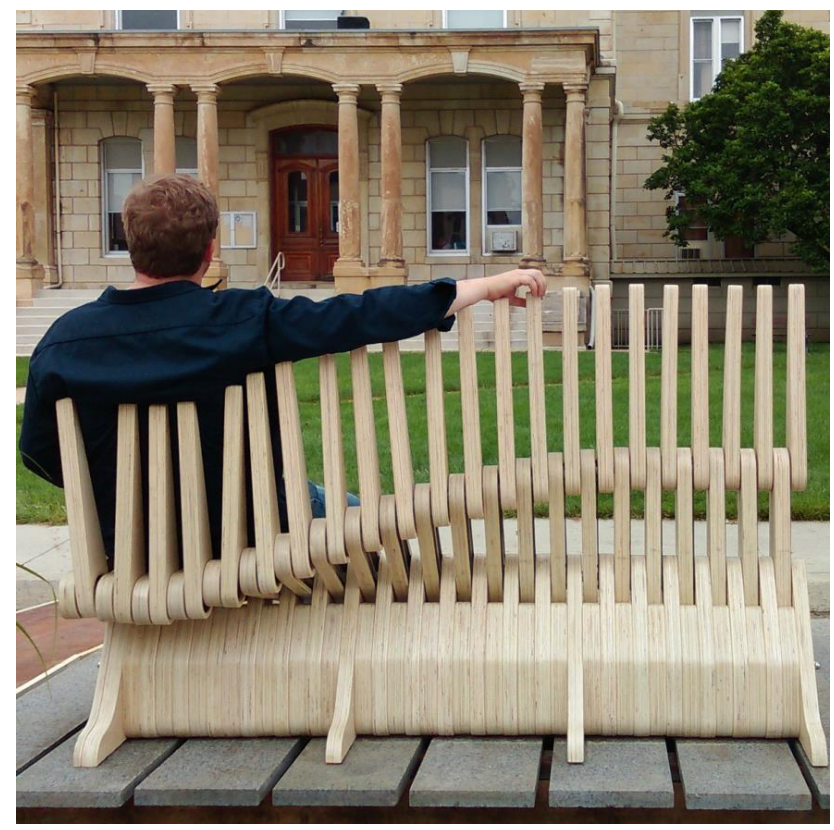

Slika 2. Talasasta klupa u eksterijeru [4]

Tvorac Talasaste klupe Brajan Li (Bryan Lee) razvijao je ideju dalje i kreirao konceptualno rešenje Talasaste klupe sa nadstrešnicom. Koncept ovog dizajna je da se oblik klupe sa nadstrešnicom prilagođava korisniku u potpunosti, i tako pored rešenja ergonomije klupe ova struktura korisniku omogućava prijatniji boravak tako što ga istovremeno štiti od sunčevih zraka, što je prikazano na slici 3.

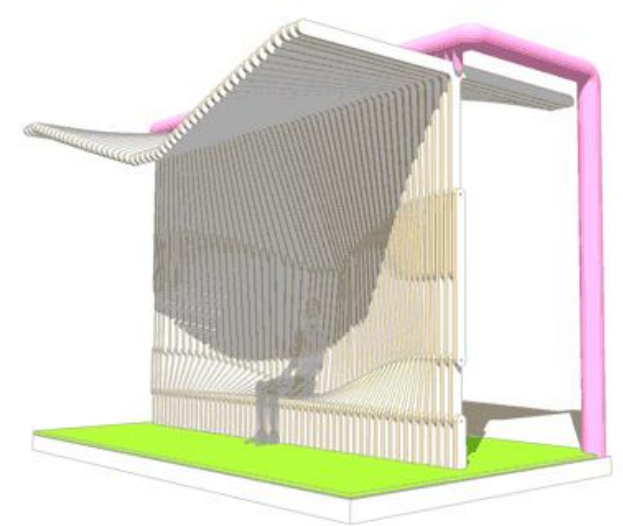

Slika 3. Konceptualno rešenje Talasaste klupe sa nadstrešicom [5]

Ideja pomerljive klupe sa nadstrešnicom predstavlja velik napredak u kreiranju ulične opreme, jer promenjivom formom rešava više problema istovremeno. Inovativni koncept kao što je ovaj, na samom početku ima mnogo potencijala za dalje unapređivanje i razrađivanje.

\section{METODE ISTRAŽIVANJA}

Pomenuti primeri poslužili su kao inspiracija za kreiranje koncepta kinetičke klupe sa nadstrešnicom sačinjene od segmenata. Naime, ideja je da struktura zadovolji više korisničkih potreba istovremeno, kao i estetske kriterijume, a da pri tome ne iziskuje prekomerno trošenje materijala. Novo rešenje će tako imati sedište koje se rotira oko jednog horizontalnog elementa, slično IDO strukturi sa dodatkom nadstrešnice koja će se pomerati zajedno sa segmentima sedišta i naslona. Gornji deo strukture će tako činiti dva pravolinijska elementa, jedan koji predstavlja nadstrešnicu i drugi koji je povezuje sa sedištem. Nadstrešnica i poveznica će se rotirati zajedno sa sedištem i naslonom, što se vidi na slici 4 , pa se za razliku od Talasaste klupe sa nadstrešnicom neće praviti po jedna nadstrešnica sa svake strane, te će doći do uštede materijala.
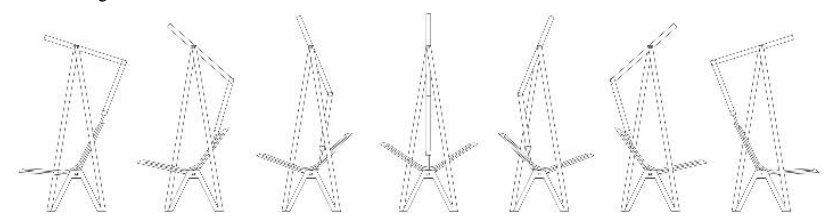

Slika 4. Prikaz koncepta rotacije kinetičke klupe sa nadstrešnicom

Kako je ideja da se svi pomenuti elementi rotiraju istovremeno, veze koje ih spajaju moraju biti osmišljene tako da jedan element ne sprečava rotaciju drugog. Element sedišta rotiraće se oko donjeg, a element nadstrešnice oko gornjeg horizontalnog elementa, pri čemu ovi fiksni horizontalni elementi moraju biti u istoj vertikali kako bi struktura ostala simetrična. Na mestu gde se ova dva pokretna elementa rotiraju oko horizontalnih osa rotacija, mora postojati metalno ojačanje kako bi se sprečilo habanje.

Takođe, na metalnim elementima veze postoji pločasti dodatak koji će predstavljati razdelnik između profila prikazan na slici 5 , koji će omogućavati rotaciju celog profila u jednoj ravni.

Veza poveznice i nadstrešnice predstavljaće zglob postavljen na zasečenim krajevima ova dva elementa, dok će poveznica na drugom kraju imati metalni produžetak koji će se kretati po unutrašnjem zaseku elementa sedišta i naslona, kao na slici 6 .

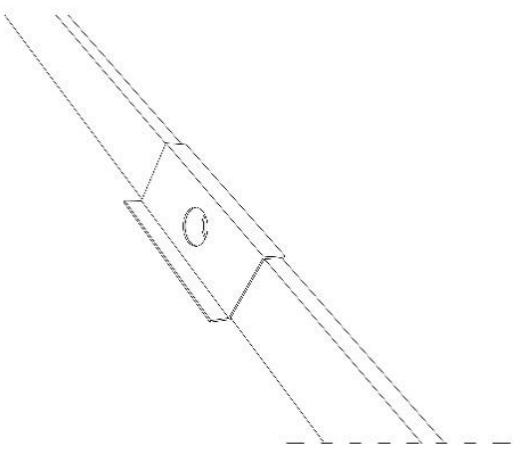

Slika 5. Element veze nadstrešnice sa gornjom osom rotacije koji je ujedno i razdelnik profila

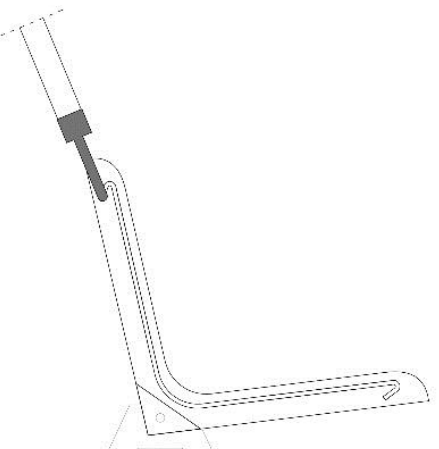

Slika 6. Element veze poveznice i sedišta 
Pored spojnih veza, za kreiranje kinetičke klupe sa nadstrešnicom bitnu ulogu igra dimenzionisanje elemenata. Kako bi se taj proces olakšao, kreiran je kod u Grashoperu (Grasshopper) koji predstavlja vizuelni programski jezik i pokreće se zajedno sa Rajnom (Rhinoceros 3d computer -aided design). Modelovanje klupe sa nadstrešnicom pomoću Grashoper koda pruža mogućnost brzog proračuna svih dimenzija nakon promene bilo kog parametra.

Element od čije dužine zavisi da li će struktura moći da se transformiše je poveznica. Ta dužina mora biti precizno određena, pri čemu zavisi od sledećih faktora: visine donje i gornje tačke rotacije elemenata od tla, kao i od dužine elementa nadstrešnice. Zbog toga, njena dimenzija se određuje pomoću kružnice koja ima centar u gornjoj tački rotacije i prečnik željene dužine nadstrešnice, od koje se meri najkraće rastojanje do donje tačke rotacije. Izračunato rastojanje predstavljaće poluprečnik kružnice koja ima centar u tački koja se prilikom rotacije elementa sedišta kreće po istom. Dakle, centar te druge kružnice predstavljaće početnu tačku linije poveznice, dok se drugi kraj poveznice pronalazi u odgovarajućoj presečnoj tački dve pomenute kružnice, što se jasnije može sagledati na slici 7 .

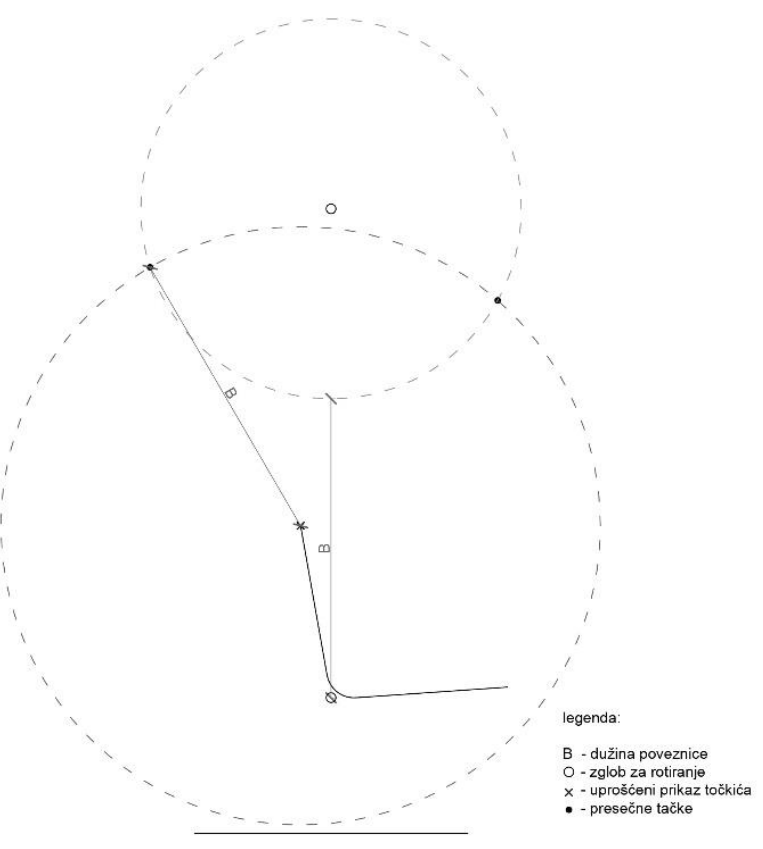

Slika 7. Grafički prikaz dimenzionisanja poveznice

Kod kreiran na ovaj način pored mogućnosti promene dimenzija svih elemenata i proračuna dimenzije poveznice, daje mogućnost promene debljine profila $\mathrm{i}$ njihovih međuosbnih razmaka. Kako takve promene mogu u velikoj meri uticati na efektivnost klupe u zaštiti od sunčevog zračenja, na udobnost kao i ekonomičnost klupe, takve mogućnosti su veoma značajne za kreiranje optimalnog rešenja klupe sa nadstrešnicom. Promenom sledećih parametara: visina gornje tačke rotacije, dužina nadstrešnice, širina elemenata profila klupe i širina međusobnog razmaka profila, kreiraju se varijacije na kojima se vrši analiza osunčanosti.

Analiza osunčanosti vrši se takođe u Grashoperu, pomoću alata Lejdibag (Ladybug) koji omogućava grafički i numerički prikaz broja časova tokom kojih je neka površ izložena sunčevom zračenju u toku određenog perioda. Kreirane varijacije različitih dimenzija elemenata klupe biće analizirane pomoću Lejdibaga tako što će se postaviti tri površi (u visini temena, ramena i kolena) ispod nadstrešnice. Poređenjem dobijenih rezultata pronalazi se optimalno rešenje za datu situaciju koje podjednako zadovoljava zahteve zaštite od sunca, udobnosti i ekonomičnosti.

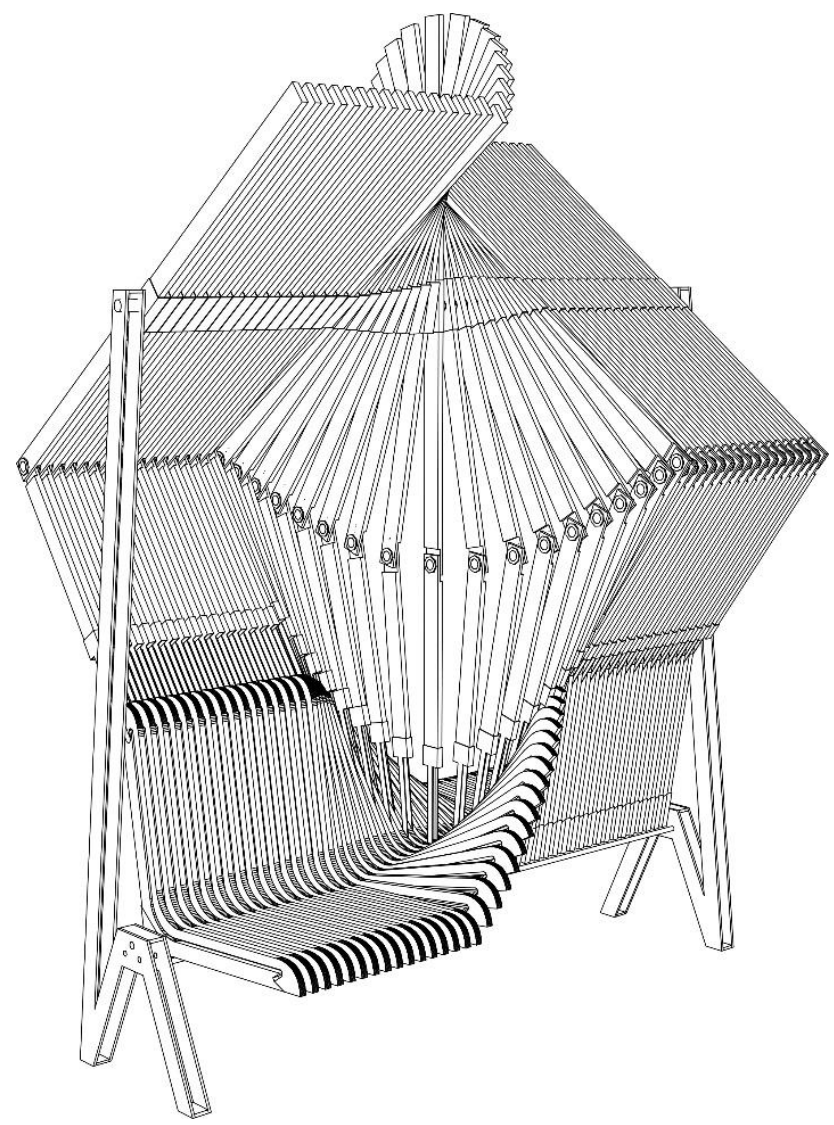

Slika 8. Prostorni prikaz klupe sa nadstrešnicom

Pored elemenata klupe koji se pomeraju, postoje i fiksni elementi koji nose konstrukciju i učvršćuju je za tlo. Fiksni elementi su bočni nosači i horizontalni elementi oko kojih se rotiraju elementi nadstrešnice i elementi sedišta i naslona. Osim ovih, postoje još dva horizontalna elementa koji se nalaze pored donje ose rotacije (sa svake strane po jedan) i služe za ograničenje ugla rotacije sedišta i naslona. Bočni nosači imaju izgled izlomljene linije, koja kreće od tla do donje tačke rotacije, ide ponovo do tla, a zatim se penje do gornje tačke rotacije.

Dimenzije bočnih nosača zavise od visine gornje i donje tačke rotacije, a dužina horizontalnog nosača od potrebne širine klupe. Postavljanje ove klupe na različite pozicije $u$ odnosu na strane sveta može davati drugačije rezultate analize osunčanosti, te dimenzije elemenata klupe sa nadstrešnicom mogu biti različite. Struktura klupe sa nadstrešnicom prikazana na slici 8 predstavlja prostorni prikaz jedne od varijanti kreiranih za potrebe analize osunčanosti. Na pomenutom prostornom prikazu može se videti da je kreirana struktura veoma dinamična i autentična, čime može doprineti stvaranju prepoznatljive slike naselja. 


\section{ZAKLJUČAK}

Prilikom kreiranja kinetičke strukture kao elementa urbanog mobilijara treba voditi računa jednostavnosti dizajna, kao i dimenzionisanju koje teži što većoj univerzalnosti. Kako će se takav dizajn nalaziti na javnom mestu gde će ga koristiti veliki broj korisnika različitih fizičkih karakteristika, njegove dimenzije moraju omogućiti ugodno korišćenje svima. Takođe, jednostavnost principa transformacije je veoma bitna, kako bi mogućnosti strukture bile odmah uočljive i rado korišćene.

Već je pomenuto da je kreiranje kinetičkih struktura veoma složen proces u kom se velika pažnja mora posvetiti proračunima i dimenzionisanju, te je upotreba Grashopera taj proces u velikoj meri olakšala. Prednost ovakvog vida razvoja ideje je u njegovoj prilagodljivosti različitim faktorima i različitim lokacijama. Pored toga, mogućnost analize osunčanosti više različitih varijanti istog koncepta pomoću Lejdibag alata predstavlja značajan korak u nalaženju optimalnog rešenja.

\section{LITERATURA}

[1] M. A. Fox, B. P. Yeh, „Intelligent Kinetic Systems“, in Managing Interactions in Smart Environments, P. MANSE'99, Dublin, IRL, December 1999, P. Nixon, G. Lacey, S. Dobson, Eds. Springer, London, 2000, pp. 91
[2] C. Sanchez-del-Valle, ,,Adaptive Kinetic Structures: A Portal to Digital Prototyping “, Proceedings ACADIA'05: „Smart Architecture“, Octobar 13-16, 2005, Savannah, Georgia, SCAD, 2005

[3] https://euipo.europa.eu/ohimportal/en/designeuropafinalistsido?p_p_id=qlpopup_WAR_qlpopupportlet\&p_p_life cycle $=0 \&$ p_p_state $=$ pop_up/sv/hu (pristupljeno u junu 2020.)

[4] https://archinect.com/people/project/46609126/articul ated-seating/122823779 (pristupljeno u junu 2020.)

[5] https://www.core77.com/posts/56212/ArticulatedSeating-With-Wavy-Style (pristupljeno u junu 2020.)

\section{Kratka biografija:}

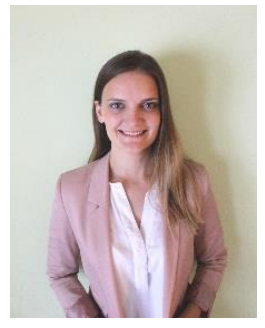

Milica Terzin rođena je u Somboru (Republika Srbija) 1995. god. Nakon završenih osnovnih akademski studija 2018. godine na Fakultetu tehničkih nauka, smer arhitektura i urbanizam, master rad iz oblasti Digitalnog dizajna u arhitekturi i urbanizmu odbranila je 2020. godine.

kontakt: terzinmilica.95@gmail.com 